\title{
Laryngo-onycho-cutaneous syndrome: an inherited epithelial defect
}

\author{
Roderic J Phillips, David J Atherton, Martin L Gibbs, Stephan Strobel, Brian D Lake
}

Hospital for Sick Children, London, Host Defence Group Roderic J Phillips David J Atherton

\section{Ophthalmology} Department Martin L Gibbs

\section{Histopathology} Department Brian D Lake

\section{Correspondence to:}

Dr Rod Phillips, Department

of Paediatrics, Royal

Children's Hospital

Parkville, Victoria 3052,

Australia.

Accepted 31 August 1993 Stephan Strobel

\begin{abstract}
Three children with an unusual but clearly defined combination of clinical findings that appear to have been inherited in an autosomal recessive manner are described. All had developed laryngeal abnormalities, chronic skin ulceration, nail dystrophy, and conjunctival disease in infancy. In every case, dental enamel was hypoplastic and both skin and mucosal surfaces demonstrated increased susceptibility to trauma. Progression of disease occurred, to life threatening respiratory obstruction in two cases and to effective blindness and fatal respiratory obstruction in the third child. All of these children came from the Pakistani ethnic group. No medical treatment has halted progression of this disease but laser therapy has been partially successful in alleviating laryngeal manifestations.

Ultrastructural and immunohistological examination of unaffected skin was undertaken in each child. No abnormality was found in the child with the mildest clinical disease. Both of the other children showed abnormal hemidesmosomes on ultrastructural examination. The most severely affected child also had abnormally weak immunoreactivity with antibodies G71 and GB3 directed against basal cell $\alpha 6 \beta 4$ integrin and the basement membrane glycoprotein nicein respectively. These abnormal findings are also seen in skin from patients with junctional epidermolysis bullosa.

These three children have the laryngoonycho-cutaneous syndrome, which may not be rare in their ethnic group. The available clinical and pathological
\end{abstract}

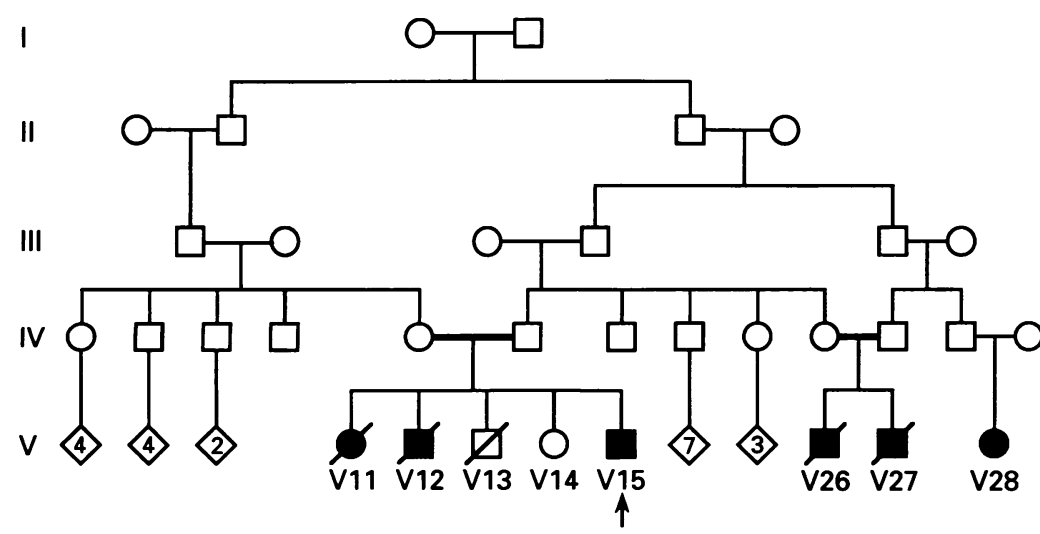

Figure 1 Family pedigree of patient 1. The arrow indicates the proband (V15). Four relatives (a sister, V11, a brother, V12, and two male cousins, V26 and V27) were similarly affected and died in childhood. An affected female relative, V28, is alive. One brother, V13, died of unknown causes at 1 week of age. Open circles represent normal females, open squares are normal males, and diamonds do not specify gender. evidence is consistent with this syndrome being caused by an inherited defect affecting the lamina lucida of the skin basement membrane zone. The laryngoonycho-cutaneous syndrome may therefore represent a new and distinctive type of junctional epidermolysis bullosa. (Arch Dis Child 1994; 70: 319-326)

Over a period of one year, three children presented with an unusual combination of clinical problems. Each had developed a hoarse voice in the neonatal period and skin, nail, and conjunctival lesions during infancy. They shared a syndrome only recently recognised outside Pakistan and this study was designed to identify the features and the aetiology of the disease.

\section{Case reports}

PATIENT 1

This boy was the fifth child of consanguineous Pakistani parents and was normal at birth. At 1 week of age his voice became hoarse, and by 6 months several toenails had become thickened. From 8 months of age he had many episodes of soreness and swelling around his eyes. Sites of trivial skin trauma sometimes healed normally but occasionally failed to re-epithelialise, developing instead into indolent ulcers. Two fingernails that were lost after minor trauma regrew normally. Transient small blisters were observed on a few occasions on his skin and oral mucosa. He had recurrent bleeding from his gums.

Five of his relatives in Pakistan had the same syndrome (fig 1). Of these, two siblings (V11 and V12, fig 1) died of progressive respiratory obstruction, at age 3 years (V11) and 6 years (V12) respectively. No details were available concerning the mode of death of two cousins at age 3 years (V26) and age 4 years (V27). The fifth affected relative (V28) was alive at age 16 years. One further sibling (V13) died of unknown causes at 1 week of age without showing any features of the syndrome.

When first seen by us at 4 years of age, patient 1 was a lively boy of normal growth and development who conversed readily, but only in a whisper. At the lateral aspect of each eye, mild symblepharon was present with local adhesions between the contiguous bulbar and tarsal conjunctiva and adjacent lid margins (fig 2A). A slender frond of pink, moist tissue arose from this fused conjunctival tissue. Elsewhere, and in the fornices, the conjunctiva appeared normal. The abnormalities in each eye were virtually identical. The vision was unimpaired. 

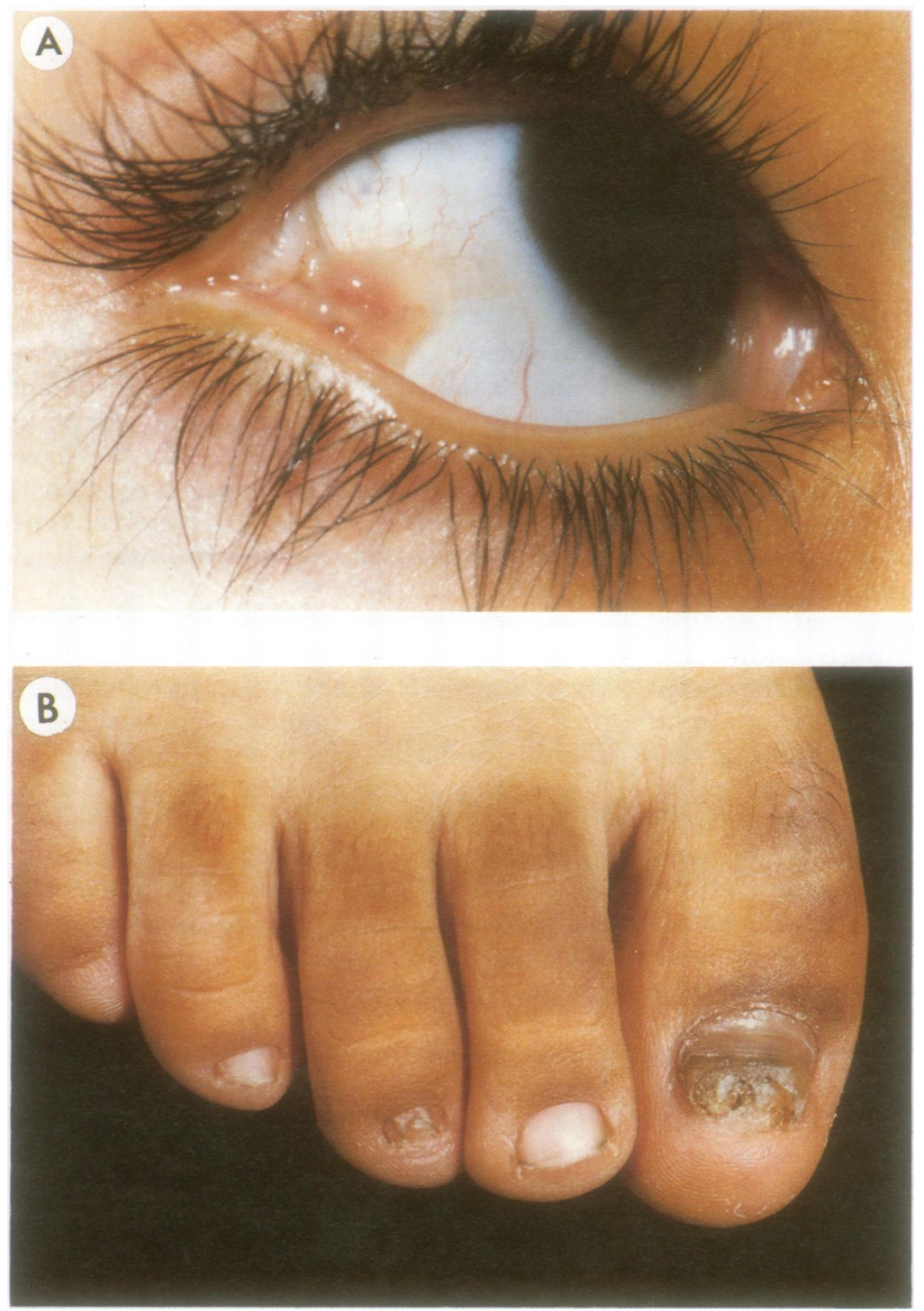

Figure 2 Patient 1. (A) Right eye. A normal plica semilunaris can be seen at the medial canthus; (B) toes of right foot.

The nails of the third digits of both hands and the first and third digits of both feet were thickened and irregular without associated inflammation (fig 2B), and the fifth toenails had been lost. There were small ulcers on his hard palate and on his right pinna, and some areas of minor scarring, particularly on both ears. Hair and skin was otherwise normal and no blisters could be induced by rubbing. His teeth showed hypoplastic enamel covered with a black extrinsic stain, interpreted as due to chromogenic bacteria. There was no evidence of caries.

Direct laryngoscopy under anaesthesia showed an extreme degree of obstruction of the airway by a laryngeal web and by large supraglottic and glottic nodules (fig 3); these were partially removed by carbon dioxide laser. The polypoid mass in his left eye was surgically removed. Histopathology of laryngeal tissue and of the conjunctival polyp showed acute and active chronic inflammatory granulation tissue with no specific features. The results of other investigations are given below.

Over the following year, progressive enlargement of his airway was achieved with repeated laser treatment. No regrowth of abnormal laryngeal tissue occurred between treatments. The polyp removed from his left eye recurred within two months and further proliferation of conjunctival tissue occurred in each eye. When last seen, this bound the lateral quarter of both lid margins and the contiguous bulbar conjunctiva together, giving rise to marked symblephara. He remained otherwise well.

\section{PATIENT 2}

This girl was the younger of two children of consanguineous Pakistani parents. She was normal at birth, but within two weeks had developed a hoarse voice and, on the back of her right wrist, transient blisters that became chronic ulcers. By 6 months of age, these had healed but several other ulcers had developed, none preceded by blisters. Many of her nails were abnormal, some with persistent paronychia. She had recurrent eye soreness and nose bleeding. These problems continued despite trials of steroid eye drops, antibiotics given systemically, topically or as eye drops, and nine months of oral antituberculous treatment. In other respects she remained well. No other family member has had problems similar to those experienced by this patient.

When first seen by us at 3 years of age, she was an active child with normal development and a hoarse voice. She was mildly photophobic and had large conjunctival masses extending medially from the lateral canthus to the corneoscleral limbus in both eyes.
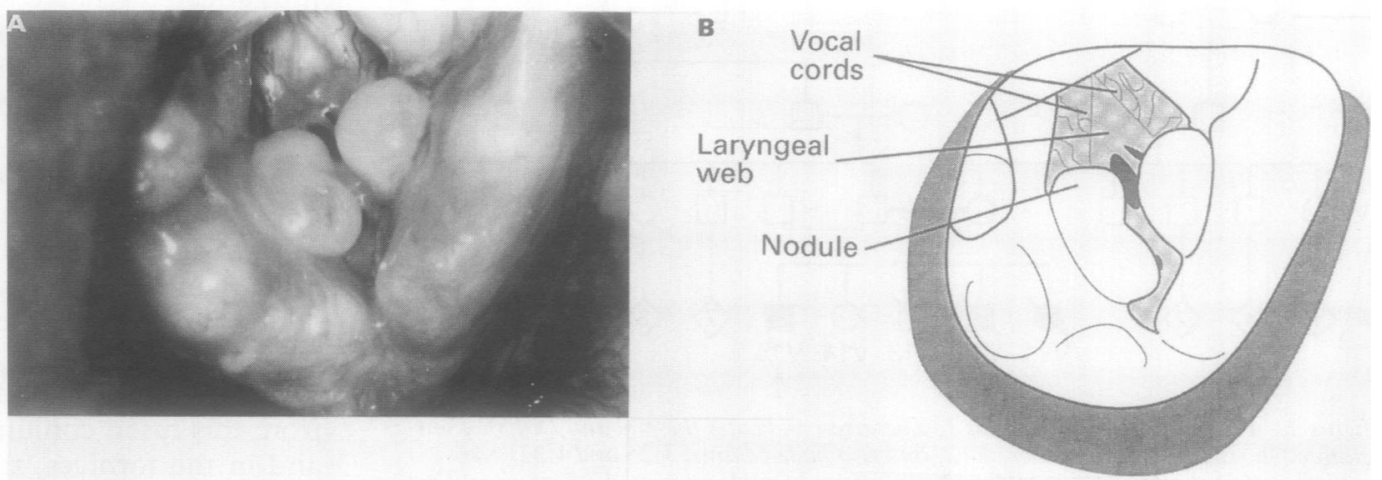

Figure 3 Patient 1. (A) Larynx as seen at laryngoscopy, showing almost total obstruction of the airway by a laryngeal web and multiple nodules; (B) key to $(A)$. 


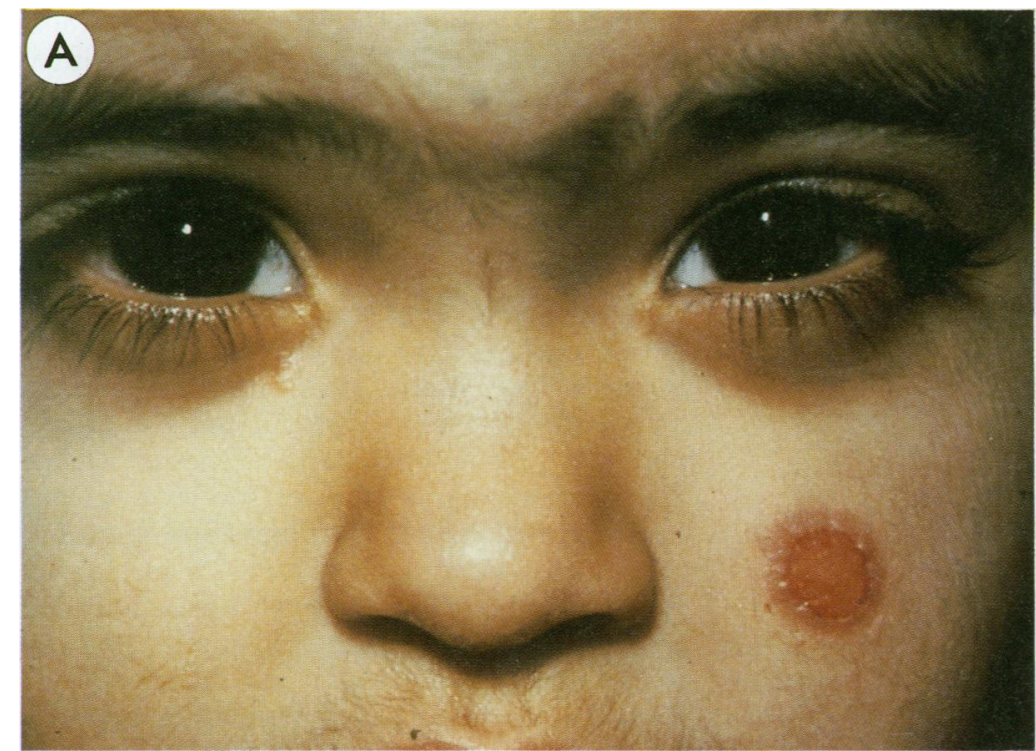

Figure 4 Patient 2. (A) Face; (B) first toe, left foot.

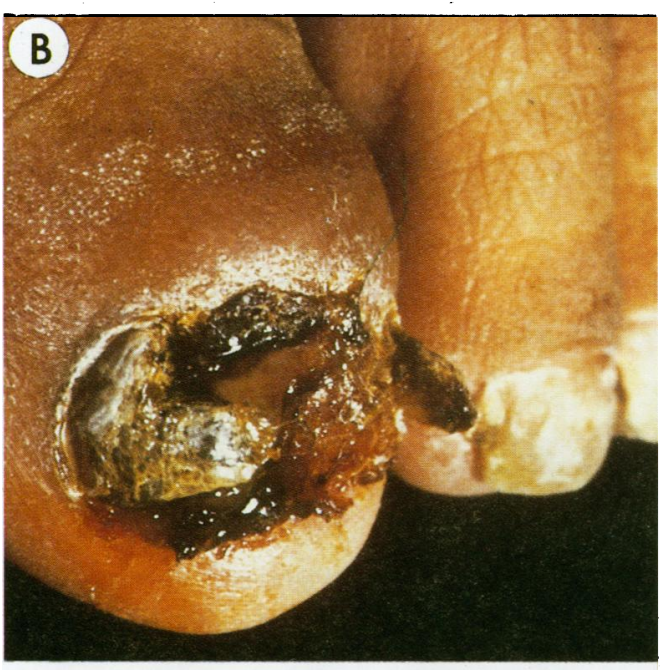

The abnormal tissue bound the lid margins and contiguous bulbar conjunctiva together, resulting in extensive symblepharon formation. In addition, a polypoid mass was noted to arise separately from the conjunctiva lining the medial aspect of the left upper lid. The remain-

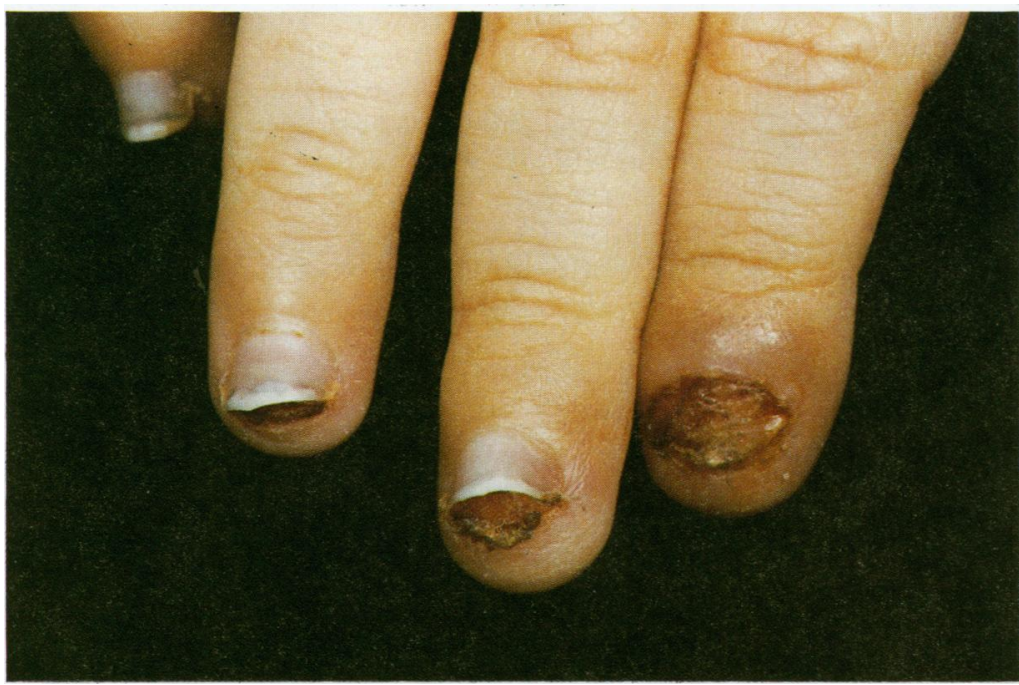

Figure 5 , Patient 3, aged 4 months. Fingernails on right hand. ing conjunctiva appeared normal. Superficial corneal scarring was present on the left, consistent with previous corneal epithelial ulceration, but vision was unaffected. On her left cheek, there was a shallow, well demarcated ulcer with a raised purple edge but no surrounding inflammation (fig 4A). Other ulcers were present on her ears, back, and forearms. Skin and hair were otherwise normal. The nails of the first and fifth toes of each foot were irregular, horny masses with surrounding inflammation (fig 4B). Other toenails and fingernails were variably affected. Her teeth were small with hypoplastic enamel.

Direct laryngoscopy under anaesthesia showed a thin anterior web with overlying soft polypoid mucosa which was partially removed by carbon dioxide laser. Laryngeal biopsy was unsuccessful. Histopathology of a section of one conjunctival mass showed granulation tissue with mixed acute and chronic inflammatory cell infiltration. The results of other investigations are given below.

She was treated with iron and zinc supplements, and with steroid eye drops. During follow up over two years, no improvement was noted in the lesions affecting her skin or nails, and the conjunctival granulation tissue became more extensive.

\section{PATIENT 3}

This boy was the first child of unrelated Pakistani parents. He was normal at birth, but, within a week, his voice was noted to be soft. At this time, he received a barely noticeable scratch on the right cheek which, instead of healing, slowly developed into an indolent ulcer. Removal of an adhesive plaster covering this first ulcer resulted in a second ulcer on adjacent unaffected skin, and a third developed under the waistband of his nappy. Over subsequent months, ulcers occurred in both axillae and over the occiput, and his circumcision scar repeatedly broke down. Over the same period, all of his nails became abnormal. In each case, proliferating tissue gradually lifted a previously normal nail off the nail bed, commencing distally. Several were shed and paronychia developed in some. He bled frequently from skin ulcers, nail beds, gums, mouth, and nose. He had sore eyes from the age of 3 months. Treatment with oral flucloxacillin, griseofulvin, and ketoconazole produced no change in his condition. There is no family history of similar disease.

When first seen by us at 4 months of age he showed normal growth and development. He had oedematous eyelids and was photophobic. Ocular examination revealed thickened, congested bulbar conjunctiva at both lateral canthi and directly inferior to the cornea. There was no proliferation or symblepharon formation and the remaining conjunctiva appeared healthy. The epithelium over the inferior aspect of both corneas was loose and sloughed readily. Vision, however, appeared normal. Skin texture was normal, and blisters were not induced by handling or rubbing. Shallow, crusted ulcers were present on both cheeks, on 

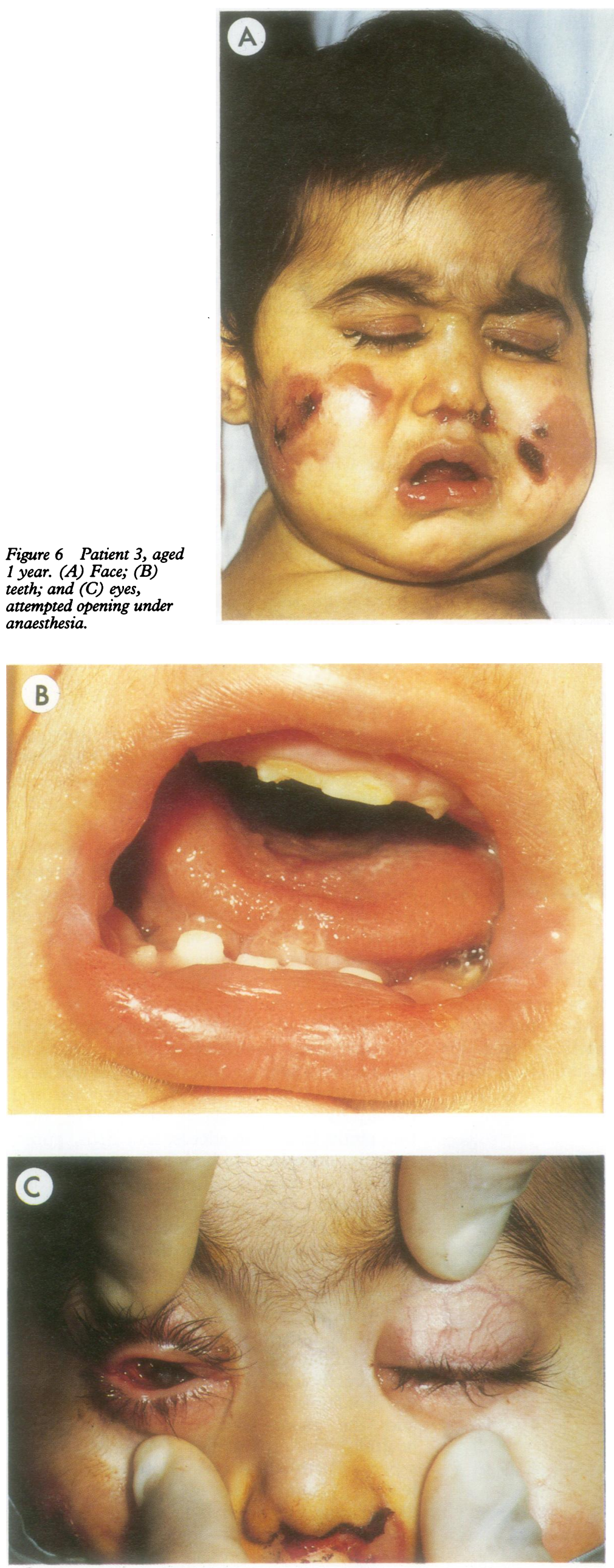

the occiput, in both axillae, on the right elbow and on his flank. All nails had either been lifted up from the nail bed by what appeared to be a mass of granulation tissue (fig 5) or had been lost completely, leaving oozing or crusted granulation tissue. No other abnormalities were noted.

Direct laryngoscopy under anaesthesia showed normal vocal cords with swollen supraglottic tissues. The oropharyngeal and nasal mucosa was friable with marked contact bleeding. Biopsies of the supraglottic tissue, abnormal conjunctiva, and the edge of the ulcer on his elbow showed no evidence of bacteria, mycobacteria, or fungi despite the use of special stains and culture. Histopathology of all these specimens showed ulceration and acutely inflamed granulation tissue without granulomas, giant cells or other specific features. The results of other investigations are given below.

Over the subsequent 12 months, moderately severe anaemia (haemoglobin concentration $62 \mathrm{~g} / \mathrm{l}$ ) responded to iron supplements, but progression of the disease continued despite trials of prednisolone ( $3 \mathrm{mg} / \mathrm{kg} /$ day), zinc, sulphapyridine, vitamins, and potent steroid eye drops. He failed to thrive (weight $8.6 \mathrm{~kg}$ at 16 months) and continued to lose blood from pharyngeal, skin (fig 6A), and nail bed lesions. Ulceration at the penile meatus led to stricture formation, chronic urinary obstruction, and the need to repeatedly open the meatus under local anaesthesia. Focal masses, presumed to be granulation tissue, developed at the gingival margin. The enamel of all eight incisors was hypoplastic and the upper incisors had progressively worn down to gum level (fig 6B). Proliferation of conjunctival tissue was more marked than that seen in patients 1 and 2 and led to total occlusion of his left palpebral fissure and almost total occlusion of his right (fig 6C). An oculoplastic procedure was performed in which the adhesions between the upper and lower eyelids and between the lids and the globe were divided bilaterally, excess tissue was excised, and scleral shells were inserted. However, within weeks the adhesions reformed and his vision became severely obstructed again.

In addition to the above problems, he also developed worsening stridor. Direct laryngoscopy on two occasions showed increasing epiglottic and supraglottic oedema with ulceration and contact bleeding, swollen and poorly defined vocal cords, and a normal trachea. He died at 18 months of age as a direct result of upper airway obstruction. Permission for postmortem was declined.

\section{Methods}

Shave skin biopsies of clinically unaffected skin were taken and prepared for ultrastructural and immunohistological examination as previously described. ${ }^{1}$ Immunohistological mapping of the basement membrane zone was performed using three antibodies. Two of these, LH7.2 directed against epitopes on collagen type VII as found in anchoring fibrils 

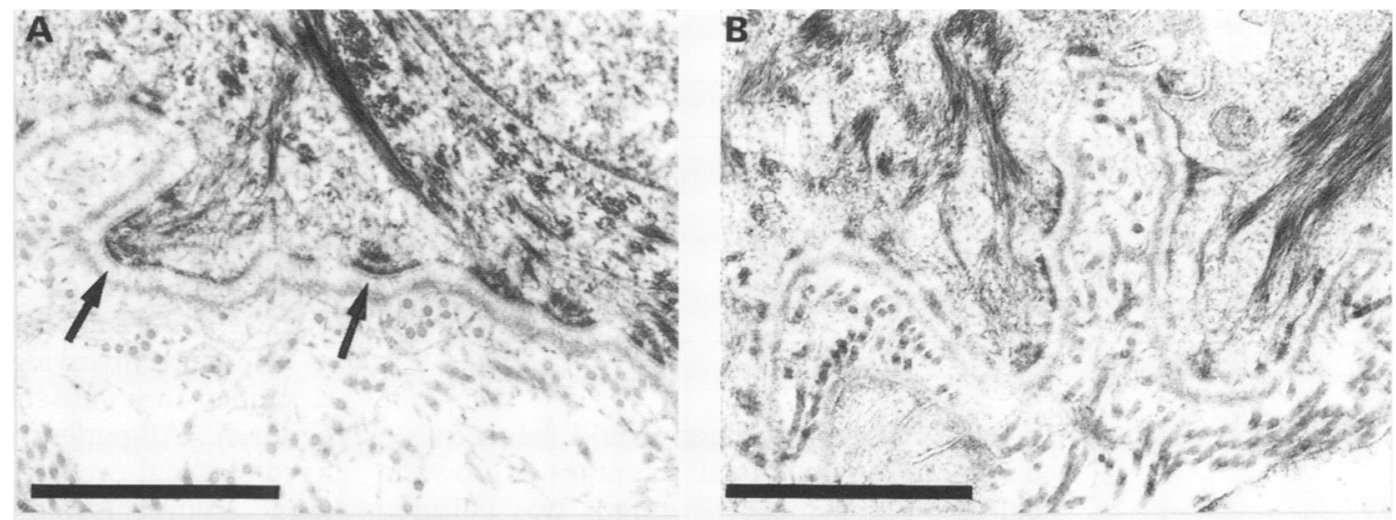

Figure 7 Electron micrographs of the dermoepidermal junction in skin from $(A)$ patient 1 and $(B)$ patient 3. In $(A)$ normal hemidesmosomes can be seen (arrows). In (B) hemidesmosomal attachment plaques and subbasal dense plates are poorly defined. Scale mark $=1$ micron.

and GB3 directed against the basement membrane glycoprotein nicein in the lamina lucida, were used as previously described. ${ }^{1}$ The third antibody, G71, a gift from Dr John

\section{A}
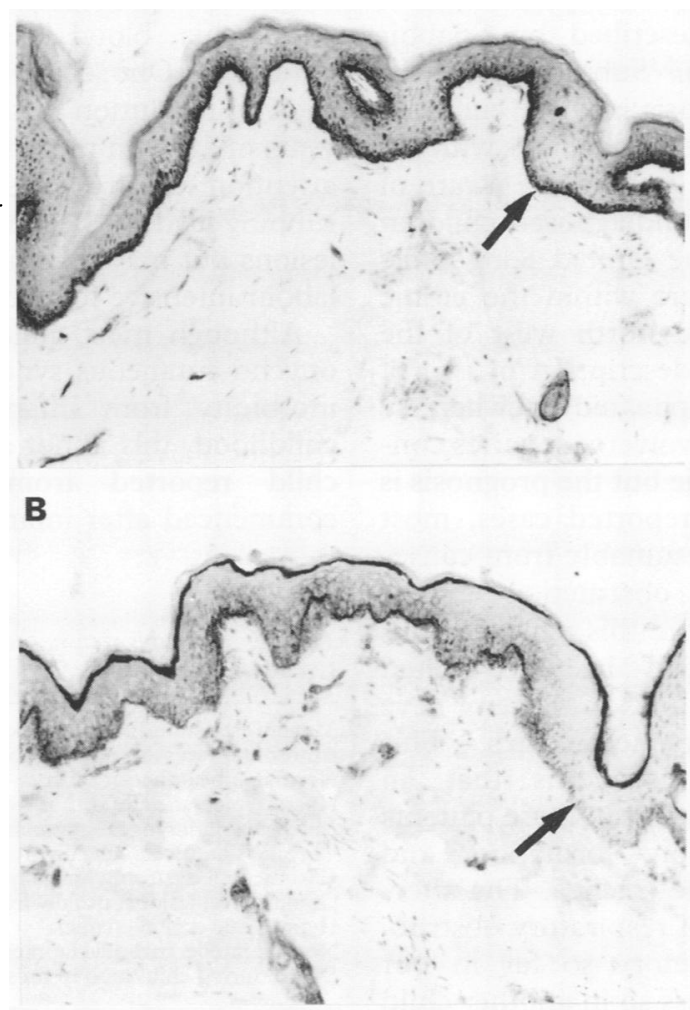

C

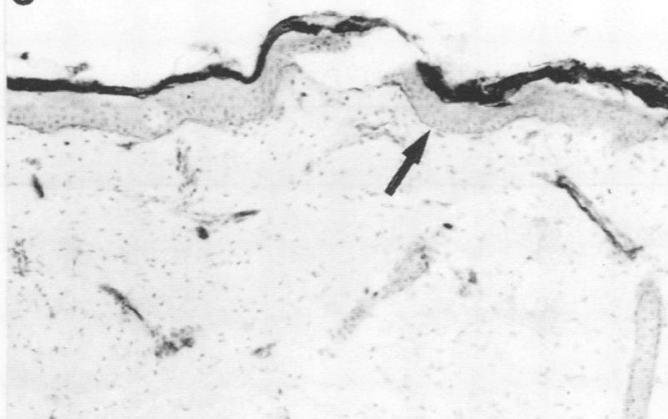

Figure 8 Antibody 671 immunoperoxidase binding at the basement membrane zone (arrowed) in $(A)$ patient 2 , showing normal immunoreactivity; (B) patient 3, showing weak and patchy immunoreactivity; and $(C)$ a child with junctional epidermolysis bullosa, showing absent immunoreactivity $(\times 110)$.
Aplin, is directed against the $\beta 4$ subunit of the integrin $\alpha 6 \beta 4$ complex ${ }^{23}$ which is a component of hemidesmosomes. ${ }^{4}$ It was used at a dilution of 1:400 on cryostat sections.

\section{Results}

Light microscopic examination of shave biopsies of unaffected skin was normal in all three patients. Results of ultrastructural (fig 7) and immunohistochemical (fig 8) examination are given in table 1. Other tests which gave an abnormal result in any patient are listed in table 2 . The results of the following investigations were normal.

Haematology: white cell count and differential, reticulocyte count, haemoglobin electrophoresis, $C$ reactive protein, coagulation studies, bleeding time, and sickle cell trait.

Biochemistry: concentrations of glucose, urea, sodium, potassium, calcium, magnesium, phosphate, creatinine, bilirubin, copper, zinc, selenium, folate, vitamin B12, vitamin $\mathrm{A}$, retinol binding protein, amino acids, and organic acids and activities of alkaline phosphatase and aspartate transaminase, and chromosomes.

Immunology: IgG, IgA, IgM, IgE, radioallergosorbent test (milk, egg, wheat, house dust mite), isohaemagglutinins, nitroblue tetrazolium test for neutrophil oxidative function, $T$ cell subsets (CD2, CD3, CD4, CD8, CD14, CD16, CD19, CD56), lymphocyte phytohaemagglutinin stimulation, leucocyte adhesion molecules (CD11A, CD11B, CD18), staphylococcal killing, autoantibodies to antinuclear antibody, extractable nuclear antibody, reticulin, mitochondria, antineutrophil cytoplasmic antibody, gastric parietal cell (weakly positive patient 1) and smooth muscle (weakly positive patients 1 and 3), antibodies to common respiratory pathogens (present), antibodies to diphtheria and tetanus (present), fungal precipitins (absent), and the Venereal Disease Research Laboratory test.

Urine: excretion of organic acids, amino acids, and protein.

Radiology: radiography of chest, sinuses, lateral skull, neck and knee, echocardiography, cranial ultrasound, and abdominal ultrasound. 
Table 1 Histological findings in clinically unaffected skin from patients with the laryngo-onycho-cutaneous syndrome (see figs 7 and 8)

\begin{tabular}{|c|c|c|c|}
\hline & Patient 1 & Patient 2 & Patient 3 \\
\hline $\begin{array}{l}\text { Ultrastructure } \\
\text { Hemidesmosomes } \\
\text { Anchoring fibrils }\end{array}$ & $\begin{array}{l}\text { Normal } \\
\text { Normal }\end{array}$ & $\begin{array}{l}\text { Poorly defined } \\
\text { Normal }\end{array}$ & $\begin{array}{l}\text { Poorly defined } \\
\text { Normal }\end{array}$ \\
\hline $\begin{array}{l}\text { Immunohistochemistry } \\
\text { GB3 } \\
\text { G71 } \\
\text { LH7·2 }\end{array}$ & $\begin{array}{l}\text { Normal } \\
\text { Normal } \\
\text { Normal }\end{array}$ & $\begin{array}{l}\text { Normal } \\
\text { Normal } \\
\text { Normal }\end{array}$ & $\begin{array}{l}\text { Decreased } \\
\text { Decreased, patchy } \\
\text { Normal }\end{array}$ \\
\hline
\end{tabular}

Microbiology: no fungi could be seen on direct microscopy of nail scrapings or grown in culture. Staphylococcus aureus was cultured from infected nail beds in patients 2 and 3 . No other positive result was obtained from culture of blood, urine, or faeces.

\section{Discussion}

These three children and the other affected relatives of patient 1 share an unusual, well defined set of clinical features that appear to have been inherited in an autosomal recessive manner (table 3 ). This is the laryngo-onychocutaneous syndrome, described by Shabbir et al in Pakistan in $1986 . .^{5}$ Subsequent to our recognition of the diagnosis in these children, we have searched for other individuals with the features listed in table 3 and we are aware of another five, previously undiagnosed children with the syndrome in the United Kingdom. ${ }^{6}$ Hence it may not be rare within the ethnic group originating in the north west of the Indian subcontinent. A description of two of those five children has appeared elsewhere. ${ }^{78}$

The extent of organ involvement varies considerably in this syndrome but the prognosis is generally poor. Of the reported cases, most died in childhood, ${ }^{57}$ presumably from causes related to respiratory obstruction and/or secondary infection. Before this paper, deaths have not been recorded in the United Kingdom. However, three children have required permanent tracheostomies. This procedure itself raises concerns that an indwelling tracheostomy tube in these patients may induce granulation formation and obstruction distally in the trachea. The alternative of surgical relief of respiratory obstruction has proved satisfactory so far in our patients ( 1 and 2 ), but less so in another child where recurrence and extension of obstruction was observed despite three conventional excisions. It remains to be seen whether laser excision provides better long term results than other surgical methods.

Visual impairment is another major cause of morbidity. No mention of eye involvement was made in the original report of the syndrome, ${ }^{5}$ but eye abnormalities do appear to be present in the accompanying photographs and are described in a subsequent report of the same children. ${ }^{7}$ All patients in the United Kingdom have external eye involvement. Eye problems range from episodic eye pain and/or slowly progressive conjunctival scarring (for example patients 1 and 2) to complete blindness in two children. Surgery temporarily restored some vision in patient 3 but within weeks his vision was again compromised. No treatment has yet been shown to have long term benefit for the eyes in this syndrome.

The third major cause of morbidity is the chronic ulceration of skin and nails. This varies in severity from being almost asymptomatic, as in patient 1 , to the extensive ulceration with paronychia, blood loss and anaemia seen in patient 3 . One child with mild skin disease showed resolution of skin manifestations by 5 years of age. ${ }^{7}$ In more severe cases, meticulous attention to dressings and protection from rubbing leads to healing of ulcers and nail bed lesions but may take months and is extremely labour intensive for the parents.

Although most children with the laryngoonycho-cutaneous syndrome have progressive morbidity from infancy and death during childhood, this is not always the case. In one child reported from Pakistan, problems commenced after infancy, remained relatively

Table 3 Features seen in the laryngo-onycho-cutaneous syndrome

Muslim Pakistani/Indian ethnic origin

Autosomal recessive inheritance

Normal appearance at birth

Hoarse voice, usually within weeks of birth

Mucosal and laryngeal granulation

Chronic skin ulcers, usually from infancy

Chronic nail dystrophy, usually from infancy

Conjunctival lesions, usually from infancy

Hypoplastic dental enamel

Normal intellectual development in most cases

Death during childhood in most cases

Table 2 Results of investigations that were abnormal in any patient

\begin{tabular}{|c|c|c|c|}
\hline $\begin{array}{l}\text { Investigation } \\
\text { (units) (normal range) }\end{array}$ & Patient 1 & Patient 2 & Patient 3 \\
\hline $\begin{array}{l}\text { Haemoglobin }(\mathrm{g} / \mathrm{l}) \\
\text { Mean corpuscular volume (fl) }(70-86) \\
\text { Platelets }\left(150-400 \times 10^{9} /\right) \\
\text { Erythrocyte sedimentation rate }\end{array}$ & $\begin{array}{r}106 \\
68 \\
293\end{array}$ & $\begin{array}{r}102 \\
69 \\
631\end{array}$ & $\begin{array}{r}92 \\
73 \\
1090\end{array}$ \\
\hline Erythrocyte sedimentation rate & 10 & 20 & 70 \\
\hline Albumin $(g / 1)(35-55)$ & 38 & 37 & 31 \\
\hline Ferritin $(\mu \mathrm{g} / 1)(7-150)$ & 5 & 4 & 8 \\
\hline Iron $(\mu \mathrm{mol} / 1)(14-25)$ & 8 & 2 & 7 \\
\hline $\operatorname{IgG}_{1}(g /)$ & $8 \cdot 0(3 \cdot 3-7 \cdot 3)$ & $6 \cdot 4(3 \cdot 3-7 \cdot 3)$ & $2 \cdot 8(1 \cdot 1-6 \cdot 0)$ \\
\hline $\operatorname{IgG}_{2}(g / 1)$ & $2 \cdot 0(0.4-1.9)$ & $1.3(0.4-1.9)$ & $0.4(0.4-0.9)$ \\
\hline $\operatorname{IgG}_{3}(\mathrm{~g} / \mathrm{l})$ & $0.05(0.15-0.37)$ & $0.20(0.15-0.37)$ & $0.80(0.05-0.36)$ \\
\hline $\operatorname{IgG}_{4}(g / 1)$ & $0.06(0.05-0.32)$ & $0.24(0.05-0.32)$ & $0.09(0.05-0.18)$ \\
\hline C3 $(\mathrm{g} / \mathrm{l})(1 \cdot 3-5 \cdot 7)$ & $7 \cdot 0$ & $>24$ & 12 \\
\hline $\mathrm{C} 4(\mathrm{~g} / \mathrm{l})(0 \cdot 2-0 \cdot 7)$ & 0.8 & $>2.5$ & $>2.5$ \\
\hline Immune complexes & Absent & Present & Present \\
\hline
\end{tabular}

*If normal range is not constant for all patients it is given in parentheses after the individual test result. 


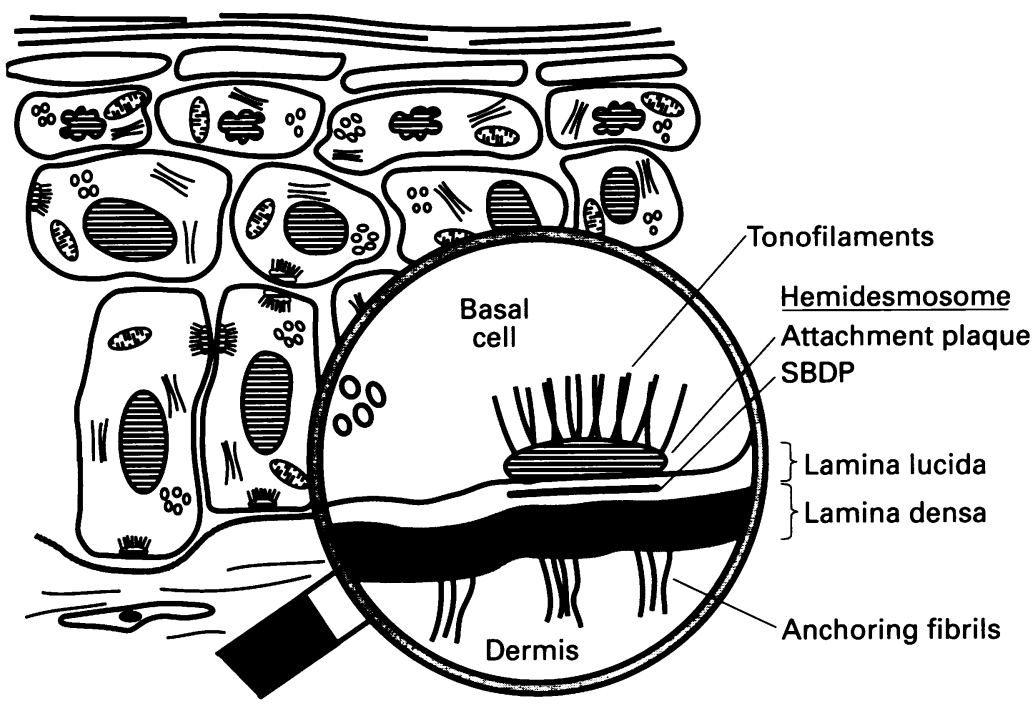

Figure 9 Structure of the dermoepidermal junction in normal skin $(S B D P=$ sub-basal dense plate). parents without showing any mechanical skin fragility. However, there are some striking similarities between the two conditions. Children with junctional epidermolysis bullosa can show involvement of:

- Larynx: hoarseness within weeks of birth is common and fatal laryngeal disease has been reported. ${ }^{9}$

- Teeth: enamel hypoplasia is usually present and can be severe. Microscopic cleavage at the dental basal lamina during development has been demonstrated. ${ }^{10-12}$

- Eyes: the progressive, extensive symblepharon formation and growth of inflammatory tissue that has been seen in the laryngoonycho-cutaneous syndrome has not been reported in junctional epidermolysis bullosa. However, small, localised symblephara between cornea and lid margin are well documented in junctional epidermolysis bullosa, as are conjunctival and corneal erosions and scarring. 1213

- Nails: virtually all patients with junctional epidermolysis bullosa show nail changes. These may be mild or may be severe with complete onycholysis, nail bed ulceration, and florid granulation tissue.

- Skin: indolent ulcers identical in appearance to those seen in patients 1-3 are common in junctional epidermolysis bullosa ${ }^{14}$ and can occur without a history of blistering.

Our conviction on clinical grounds of an association between the laryngo-onychocutaneous syndrome and junctional epidermolysis bullosa is further strengthened by (i) the blisters seen in patients 1 and 2 ; (ii) the development of an ulcer after removal of adhesive tape (patient 3); (iii) the development of ulcers at sites exposed to repeated rubbing or trivial trauma (all patients); and (iv) the first and fifth toenails always being the worst affected. All these observations suggest that an inherent epithelial weakness is present in the laryngo-onycho-cutaneous syndrome.

Some confirmation of a link between the laryngo-onycho-cutaneous syndrome and junctional epidermolysis bullosa has been provided by the electron microscopic appearance of abnormal hemidesmosomes in two of our patients (fig 7). We have also found abnormal hemidesmosomes in another patient with the laryngo-onycho-cutaneous syndrome. ${ }^{4}$ Poorly defined or rudimentary hemidesmosomes are characteristic of most patients with junctional epidermolysis bullosa. The other characteristic ultrastructural finding in junctional epidermolysis bullosa, namely a cleavage plane at the level of the lamina lucida, was not seen in our patients. However, a cleavage plane is occasionally not seen in patients with junctional epidermolysis bullosa if their skin is not particularly fragile. The absence of a split in our patients does not preclude them from having a form of junctional epidermolysis bullosa.

Of the three antibodies used in this study for immunohistochemical analysis, $\mathrm{LH} 7 \cdot 2$ and GB3 have been well characterised in epidermolysis bullosa. LH7.2 delineates anchoring fibrils and its immunoreactivity is normal in junctional epidermolysis bullosa and weak or disease typically have extreme skin fragility extensive skin blistering within days of birth This was not seen in our patients. Even the most severely affected child, patient 3 , could be handled without any precautions by his 
absent in recessive dystrophic epidermolysis bullosa. ${ }^{15} \mathrm{~GB} 3$ binds to the lamina lucida glycoprotein nicein (also known as epiligrin or BM600) ${ }^{16}$ and its immunoreactivity is weak or absent in most cases of junctional epidermolysis bullosa. The third antibody used, G71, is directed against the $\beta 4$ subunit of $\alpha 6 \beta 4$ integrin, a glycoprotein complex that is localised to hemidesmosomes and is thought to have a major role in epithelial adhesion. ${ }^{2}{ }^{3}$ The G71 antibody is therefore of considerable interest in diseases in which epithelial adhesion is deficient. We have recently shown that skin from each of nine patients with known junctional epidermolysis bullosa whom we tested showed decreased immunoreactivity with this antibody, whereas skin from patients with other forms of epidermolysis bullosa showed normal immunoreactivity. ${ }^{17}$ Thus G71 can be regarded as a useful marker for the diagnosis of junctional epidermolysis bullosa. Of our three patients, patient 3 showed abnormally weak immunostaining with both G71 (fig 8) and GB3 (table 1), again suggestive of a link between the laryngo-onycho-cutaneous syndrome and junctional epidermolysis bullosa.

It is interesting that there is a correlation between the histological findings in our patients and their clinical course. No histological abnormalities were seen in skin from patient 1 with the mildest disease, ultrastructural but not immunohistochemical abnormalities were seen in patient 2, and both ultrastructural and immunohistochemical abnormalities were present in patient 3 with the most severe and ultimately fatal disease. A similar correlation is known for junctional epidermolysis bullosa where more striking pathological abnormalities generally imply severe skin disease.

None of the histological findings in our patients are suitable for prenatal diagnosis at this time and, as yet, there is no information about the location of the genetic defect. The variability between patients in our series could be explained if several gene mutations affecting one protein are being carried by this population. Different combinations might give different clinical effects as has been shown in other diseases.

On the available clinical and pathological evidence, we would propose that the laryngoonycho-cutaneous syndrome is caused by an inherited defect affecting the lamina lucida of the skin basement membrane zone and that it may therefore represent a new and distinctive type of junctional epidermolysis bullosa. By comparison with the common 'Herlitz' form of junctional epidermolysis bullosa, the laryngoonycho-cutaneous syndrome shows little mechanical skin fragility but a greater predisposition to granulation tissue formation at sites of mild trauma. This proliferation of granulation tissue may be a secondary phenomenon related to an inability of the normal epithelial repair mechanisms to function properly in the presence of an abnormality of basement membrane adhesion. We suggest that the name laryngo-onycho-cutaneous syndrome used by Shabbir et al in their seminal work ${ }^{5}$ should at present be retained.

We are grateful to the following people for assistance (Hospitals for Sick Children unless otherwise specified): Professor G Shabbir (Mayo Hospital, Lahore); Mr D Taylor, Mr M KerrMuir (St Thomas's Hospital, London), and Mr J Collin (Moorfields Eye Hospital, London) for eye examinations, biopsies and treatment; Mr D Albert for laryngoscopic examinations, biopsies and treatment; Dr A McCartney (Institute of Ophthalmology, London) and Professor R Eady (St Thomas' Hospital, London) for helpful discussions; Mrs V Smith and Miss A Puri for expert technical assistance in electron microscopy and cytochemistry; Dr J Aplin (University of Manchester) for a gift of antibody G71; Dr G Roberts, Mr D Plint, and Miss K Harley for dental examinations; the national epidermolysis bullosa association DEBRA for financial support for purchase and maintenance of a Diatome ultramicrotome for purchase and maintenance of a Diatome ultramicrotome
$\mathrm{knife}$; and $\mathrm{Dr} \mathrm{M}$ Crock, $\mathrm{Dr} \mathrm{C}$ Crock, and $\mathrm{Mr} \mathrm{H}$ Crock knife; and $\mathrm{Dr} M$ Crock, $\mathrm{Dr} \mathrm{C}$ Crock, and $\mathrm{Mr} \mathrm{H}$ Crock
(Cromwell Hospital, London) for reviewing the manuscript.

1 Phillips RJ, Harper JI, Lake BD. Intraepidermal collagen type VII in dystrophic epidermolysis bullosa: report of five new cases. Br f Dermatol 1992; 126: 222-30.

2 Aplin JD, Sief MW. Basally located epithelial cell surface component identified by a novel monoclonal antibody technique Exp Cell Res 1985; 160: 550-5.

3 Aplin JD, Satter A, Mould AP. Variant choriocarcinoma (BeWo) cells with differing adhesion and migration to fibronectin display conserved patterns of integrin adhesion. F Cell Sci 1992; 103: 435-44.

4 Sonnenberg A, Calafat J, Janssen $\mathrm{H}$, et al. Integrin $\alpha 6 \beta 4$ complex is located in hemidesmosomes, suggesting a major role in epidermal cell-basement membrane adhesion. F Cell Biol 1991; 113: 907-17.

5 Shabbir G, Hassan M, Kazmi A. Laryngo-onychocutaneous syndrome. Biomedica 1986; 2: 15-25.

6 Phillips RJ, Strobel S, Gibbs M, Atherton DJ. Laryngoonycho-cutaneous syndrome: a new form of junctional epidermolysis bullosa? Proceedings of the British Paediatri Association Annual Meeting. Warwick, April 1992: 69.

7 Ainsworth JR, Shabbir G, Spencer AF, Cockburn F. Multisystem disorder of Punjabi children exhibiting spontaneous dermal and submucosal granulation tissue formation: logic syndrome. Clinical Dysmorphology 1992 1: $3-14$

8 Ainsworth JR, Spencer AF, Dudgeon J, Geddes NK, Lee WR. Laryngeal and ocular granulation tissue formation in two Punjabi children: logic syndrome. Eve 1991; 5: 717-22.

9 Davies $\mathrm{H}$, Atherton DJ. Acute laryngeal obstruction in junctional epidermolysis bullosa. Pediatr Dermatol 1987 4: $98-101$.

10 Winter GB. Dental problems in epidermolysis bullosa. In: Priestley GC, Tidman MJ, Weiss JB, Eady RAJ, eds Epidermolysis bullosa: a comprehensive review of classification, management and laboratory studies. Crowthorne, Berkshire: Dystrophic Epidermolysis Bullosa Research Association, 1990: 21-7.

11 Brain EB, Wigglesworth JS. Developing teeth in epidermolvsis bullosa hereditaria letalis. $B r \operatorname{Dent} 7$ 1968; 124: 255-60.

12 Holbrook KA. Extracutaneous epithelial involvement in inherited epidermolysis bullosa. Arch Dermatol 1988; 124: inherited

13 McDonnell PJ, Schofield OMV, Spalton DJ, Eady RAJ. Eye involvement in junctional epidermolysis bullosa. Arch Ophthalmol 1989; 107: 1635-7.

14 Lin AN, Carter DM, Caldwell-Brown D. Wound healing and cultured epidermal autografts in epidermolysis bullosa. In: Priestley GC, Tidman MJ, Weiss JB, Eady RAJ, eds. Epidermolysis bullosa: a comprehensive review of classification, management and laboratory studies. Crowthorne, Berkshire: Dystrophic Epidermolysis Bullos Research Association, 1990: 152-5

15 Leigh IM, Eady RAJ, Heagerty AHM, et al. Type VII collagen is a normal component of epidermal basement collagen is a normal component of epidermal basement dystrophic epidermolysis bullosa. F Invest Dermatol 1988; dystrophic epid $639-42$.

16 Domloge-Hultsch N, Gammon WR, Briggaman RA, Gil SG, Carter WG, Yancey KB. Epiligrin, the major human keratinocyte integrin ligand, is a target in both an acquired autoimmune and an inherited subepidermal blistering skin disease. $\mathcal{F}$ Clin Invest 1992; 90: 1628-33.

17 Phillips RJ, Aplin JD, Lake BD. Antigenic expression of integrin $\alpha 6 \beta 4$ in junctional epidermolysis bullosa Histopathology 1994 (in press). 